\title{
Effect of Coexposure to Methyl Ethyl Ketone (MEK) on n-Hexane Toxicokinetics in Human Volunteers
}

\author{
Jacqueline G. M. van Engelen,*,1 Wilhelmina Rebel-de Haan,* Joannes J. G. Opdam, $\dagger$ and Gerard J. Mulder \\ *Coronel Laboratory for Occupational and Environmental Health, Division of Human Toxicology, University of Amsterdam, Academic Medical \\ Centre, Amsterdam, The Netherlands; $\dagger$ Division of Occupational Toxicology and Nutrition, Department of Physiology and Kinetics, TNO Nutrition, \\ Zeist, The Netherlands; and $\ddagger$ Leiden/Amsterdam Center for Drug Research, Division of Toxicology, Leiden University, Leiden, The Netherlands
}

Received September 30, 1996; accepted February 27, 1997

\begin{abstract}
E ffect of C oexposure to Methyl Ethyl Ketone (MEK) on nHexane Toxicokinetics in Human Volunteers. van Engelen, J . G. M., R ebel-de Haan, W., Opdam, J . J . G., and Mulder, G. J . (1997). Toxicol. Appl. Pharmacol. 144, 385- 395.
\end{abstract}

In order to study the effects of methyl ethyl ketone (MEK) on the toxicokinetics of $n$-hexane and, in particular, the formation of 2,5-hexanedione from $n$-hexane in humans, volunteers were exposed to $n$-hexane (approx. $60 \mathrm{ppm}, 2.4 \mu \mathrm{m}$ in the inhaled air) with or without simultaneous inhalatory coexposure to MEK for $\mathbf{1 5 . 5} \mathrm{min}$. The concentration - time course of $\boldsymbol{n}$-hexane (in exhaled alveolar air) and its neurotoxic metabolite, 2,5-hexanedione (in serum), were studied. The concentration-time courses obtained after exposure to $n$-hexane alone were compared with those obtained after coexposure to 200 or 300 ppm MEK in the same volunteer on the same day. No effect of MEK was observed on the concentration- time course of exhaled $n$-hexane. The concentration-time course of the metabolite, 2,5-hexanedione, revealed a decrease in the rate of formation of 2,5-hexanedione (about threefold) after coexposure to MEK. Furthermore, the time to reach the peak concentration was increased from 18 to 30 min after the start of exposure. These changes in the concentration- time course of 2,5-hexanedione caused by MEK are most likely the result of inhibition of the biotransformation of one of the intermediate steps in the conversion of $n$-hexane to 2,5-hexanedione. These results indicate that the interaction of $n$-hexane and MEK leads to a decreased concentration of the neurotoxic metabolite 2,5-hexanedione (after short-term, acute exposure). () 1997 Academic Press

In occupational settings, workers are often exposed to a mixture of solvents. In most human studies, however, single solvent exposure is considered. Subsequently, in risk assessment of mixtures, the additivity principle is applied, implying that there is no interaction between the different compounds. However, such interactions might occur. For instance, certain drugs and ethanol induce cytochrome P450

\footnotetext{
${ }^{1}$ To whom correspondence should be addressed at National Institute of Public Health and the Environment, Toxicology Advisory Centre, P.O. Box 1, 3720 BA Bilthoven, The Netherlands.
}

isoenzymes, which may increase the rate of biotransformation of a solvent metabolized by such isoenzymes during coexposure. Thus, Tardif et al. (1994) reported that ethanol pretreatment affects the toxicokinetics of $m$-xylene in humans as a result of enzyme induction by ethanol. It was reported that the biotransformation of benzene to phenolic compounds in man is suppressed by coexposure to toluene. At the same time, the metabolism of toluene to hippuric acid was suppressed by benzene coexposure; both solvents are metabolized by the same cytochrome P450 isoenzymes (Inoue et al., 1988). Additional cases on interactions have been reviewed by Tardif et al. (1992) and Ikeda (1994 and 1995).

$n$-Hexane and methyl ethyl ketone (MEK) have also been reported to interact. The solvent $n$-hexane may cause peripheral and central neuropathy after chronic exposure. Its metabolite, 2,5-hexanedione, appears to be responsible for the neurotoxicity (Krasavage et al., 1980). The mechanism of toxicity has not yet been completely elucidated, but it is proposed that 2,5-hexanedione forms pyrrole adducts with neurofilaments, thereby disrupting the axonal cytoskeleton which eventually leads to nerve degeneration (DeCaprio, 1987). MEK is not itself neurotoxic, but it is known to potentiate the neurotoxicity caused by $n$-hexane after chronic coexposure (Altenkirch et al., 1978; Ralston et al., 1985). It was noticed (Altenkirch et al., 1978) in a group of glue sniffers that 18 cases of neuropathy occurred a few months after $\mathrm{MEK}( \pm 11 \%, \mathrm{v} / \mathrm{v})$ was added to an $n$-hexane-containing glue. Later, it was shown that the same phenomenon occurred in experimental animals: continuous ( $24 \mathrm{hr}, 7$ days a week, 9 weeks) exposure to MEK and $n$-hexane (100 and $400 \mathrm{ppm}$, respectively) lowered the time of onset of hindlimb paralysis of Wistar rats compared to that seen with exposure to $n$-hexane (500 ppm) alone from 9 to 8 weeks. Continuous exposure to $500 \mathrm{ppm} n$-hexane plus $200 \mathrm{ppm}$ MEK reduced the time of onset to only 5 weeks (Altenkirch et al., 1982). As 2,5-hexanedione is the neurotoxic metabolite, it was expected that coexposure to MEK somehow resulted in a higher concentration of 2,5-hexanedione. However, in some publications a decrease in 2,5-hexanedione concentration has been reported (Iwata et al., 1983; Shibata 
et al., 1990), but it should be noted that these studies considered short-term exposure.

In this study, we have investigated the toxicokinetic interaction between MEK and $n$-hexane by exposing volunteers for $15.5 \mathrm{~min}$ (acute exposure). Kinetic evaluation of the concentration-time courses of $n$-hexane in exhaled alveolar air and of 2,5-hexanedione in serum after exposure to $n$ hexane alone and after coexposure with MEK were carried out to answer the following questions: (1) Is there an effect of MEK on the toxicokinetics of $n$-hexane or 2,5-hexanedione during and after short-term exposure to concentrations around threshold limit value (TLV) concentrations? (2) Which predictions can be made of the consequences of combined exposure to these two solvents in occupational practice, based on this volunteer study?

\section{MATERIALS AND METHODS}

\section{Chemicals}

$n$-Hexane (pro analysis, 99\%), methyl ethyl ketone, (pro analysis, 99.5\%) (Merck, Darmstadt, Germany), cyclohexane, 2,5-hexanedione (Aldrich Chemie, Steinheim, Germany), 2,4-pentanedione, and pentafluorobenzylhydroxylamine (PFBHA) (Sigma Chemical Co., St. Louis, MO) were used.

\section{Subjects and Exposures}

The healthy volunteers (16 males, 3 females) were between 19 and 26 years old. They were not allowed to take alcoholic beverages for $24 \mathrm{hr}$ before the start of the experiments; none of them used any pharmaceutical drugs. All subjects gave their informed consent. This study was approved by the Medical Ethics Committee of the University of Amsterdam and the principles of the Declaration of Helsinki (1964) were followed.

The inhalation exposure procedure has been described by Opdam and Smolders (1986). Briefly, volunteers were in a sitting position and inhaled via a one-way valve, connected to a Tedlar (DuPont, DE) bag. This bag was filled with medical air, and to achieve the desired concentration of solvent vapor, solvent was introduced, at least $16 \mathrm{hr}$ before the start of exposure, using a Hamilton syringe. During exposure the total amount of exhaled air was collected in another Tedlar bag. To determine the concentration in the bags containing the inhaled and exhaled air $\left(C_{\mathrm{I}}\right.$ and $C_{\mathrm{e}}$, respectively), 1-ml air samples were withdrawn and analyzed. In addition, alveolar air was sampled and collected in a prewarmed 70-ml glass tube. This glass tube had two screw caps with rubber septa covered with a layer of Teflon (PFTE) to prevent absorption into the silicon rubber. Preceding coexposure to the $n$-hexane and MEK mixture, volunteers were exposed to 200 or 300 ppm MEK for $10 \mathrm{~min}$. Because it was anticipated that the rise in 2,5hexanedione in plasma might become important in the data analysis, the volunteers were preloaded with MEK; under those conditions the effect of MEK might be more easily measurable. Subsequently, the volunteers inhaled the mixture of $n$-hexane (approximately $2.4 \mu \mathrm{M}$ ) and MEK (200 or $300 \mathrm{ppm}$; 8.2 or $12.3 \mu \mathrm{M}$, respectively) for $15.5 \mathrm{~min}$. On the same day, 4 hr preceding or $4 \mathrm{hr}$ after the combined exposure, a reference experiment was carried out, in which the volunteers were exposed to $n$-hexane (approximately $2.4 \mu \mathrm{M}$ ) as a single solvent (Fig. 1, group 2, 3, or 4). To evaluate differences in kinetics between morning and afternoon exposure, data obtained from volunteers exposed to $n$-hexane alone both in the morning and in the afternoon were used as a control (group 1).

During exposure, the concentrations of $n$-hexane in inhaled and exhaled air were determined, as well as the breathing minute volumes and frequency. For each individual, these values are presented in Table 1.

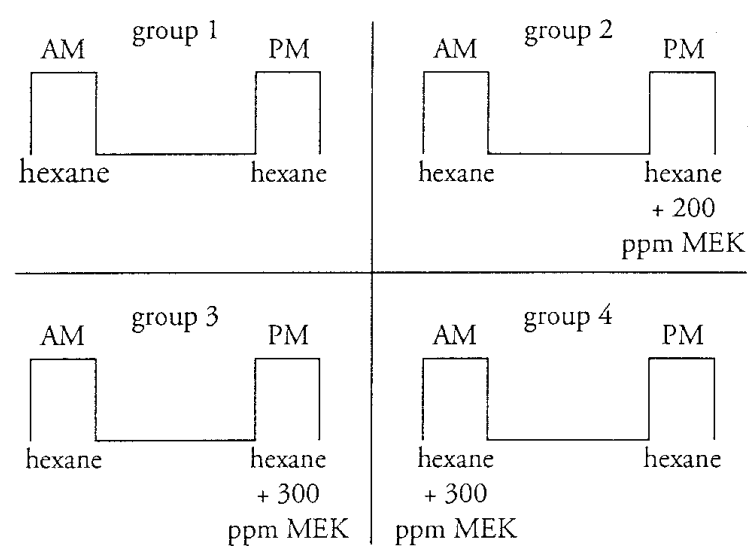

FIG. 1. Experimental design, showing the four different exposure groups used in this study. In the morning (AM) volunteers were exposed for $15.5 \mathrm{~min}$ to $n$-hexane or a combination of $n$-hexane and MEK. In the afternoon (PM), approximately $4 \mathrm{hr}$ later, volunteers were exposed again to $n$-hexane or to a mixture of $n$-hexane and MEK. The exposure concentrations of MEK are shown in Fig. 1; the concentrations of $n$-hexane for each individual are presented in Table 1.

Venous blood was obtained via a cannula (Venflon 2, $1.4 \mathrm{~mm}$ o.d., 17G; Viggo-Spectramed, Sweden) inserted into a cubital vein. To prevent blood clotting, the cannula was flushed continuously with saline using a pump (Infusa T, Medis, Milano, Italy) set at a low flow ( $5 \mathrm{ml} / \mathrm{hr}$ ); after each blood sampling the cannula was flushed with $10 \mathrm{ml}$ saline.

\section{Alveolar Air and Blood Sampling}

During and after exposure, the last part of the alveolar air was sampled after a breath-holding time of $30 \mathrm{sec}$; according to procedures described earlier (Opdam and Smolders, 1986), it can be calculated that at the the concentration in the alveolar air $\left(=C_{\text {alv,eq }}\right)$ is close to equilibrium with the concentration in mixed venous blood $\left(C_{\text {ven }}\right)$. Apart from small systematic errors, it can be assumed that the concentration-time course of $n$-hexane in alveolar air reflects the concentration-time course of $n$-hexane in the mixed venous blood. Therefore, for further data analysis we assumed that (after $30 \mathrm{sec}$ of breath-holding) $C_{\mathrm{alv}, \mathrm{eq}}=C_{\mathrm{ven}} / \lambda$, where $\lambda=$ blood/air partition coefficient of $n$-hexane. To study the fast kinetics and to describe accurately the shape of the concentration-time course, frequent sampling is necessary. During exposure and the first $30 \mathrm{~min}$ following it, samples were collected every 3-5 min. From 45 until $90 \mathrm{~min}$ after the start of exposure, alveolar air and blood were sampled every $10 \mathrm{~min}$; after this time an interval of 20 min was used. A detailed description of the toxicokinetic analysis of the data is presented in the Appendix.

\section{Chemical Analysis}

Analysis of n-hexane. Alveolar air was sampled after $30 \mathrm{sec}$ of breathholding, during and after exposure, and collected in a 70-ml glass tube. Samples $(1 \mathrm{ml})$ were drawn from the bags that contained the inhaled and exhaled air using a gas-tight 1-ml Hamilton syringe and were injected in a 70 -ml glass tube. All tubes were analyzed for $n$-hexane using a purge and trap injection system (Chrompack, Middelburg, The Netherlands) coupled to a gas chromatograph (Hewlett Packard Model 5890 A) equipped with a flame ionization detector. Through both caps of the tube a needle was inserted, and a $\mathrm{N}_{2}$-flow $(40 \mathrm{ml} / \mathrm{min})$ purged the contents of the tube for 4 min onto the cold trap $\left(-100^{\circ} \mathrm{C}\right)$. Subsequently, the trap was heated to $250^{\circ} \mathrm{C}$ in a few seconds and the contents were injected. $n$-Hexane calibration curves were prepared using a gas standard generator (Model 350, Analytical 
TABLE la

Individual Exposure Conditions Regarding the First Exposure (AM) to $n$-Hexane A lone or in Combination with MEK

\begin{tabular}{|c|c|c|c|c|c|c|}
\hline \multirow[b]{2}{*}{ First exposure (AM) } & \multirow[b]{2}{*}{ Subject } & \multirow[b]{2}{*}{$\begin{array}{l}\text { MEK } \\
(\mathrm{ppm})\end{array}$} & \multicolumn{2}{|c|}{ Hexane $(\mu \mathrm{M})$} & \multirow[b]{2}{*}{$\begin{array}{c}\text { MV } \\
\text { (liters/min) }\end{array}$} & \multirow[b]{2}{*}{$\begin{array}{c}f \\
\left(\min ^{-1}\right)\end{array}$} \\
\hline & & & $C_{\mathrm{I}}$ & $C_{\mathrm{e}}$ & & \\
\hline Group 1 & $\mathrm{~m} 10$ & 0 & 2.16 & 1.28 & 5.61 & 10.00 \\
\hline AM: $n$-hexane & m12 & 0 & 2.70 & 1.76 & 8.29 & 12.00 \\
\hline \multirow[t]{3}{*}{ PM: $n$-hexane } & $\mathrm{m} 13$ & 0 & 2.58 & 1.98 & 6.77 & 15.50 \\
\hline & m14 & 0 & 2.48 & 1.37 & 5.52 & 11.00 \\
\hline & $\mathrm{m} 11$ & 0 & 3.25 & 1.65 & 5.87 & 8.00 \\
\hline Group 2 & $\mathrm{f} 1$ & 0 & 2.26 & 1.22 & 7.10 & 15.00 \\
\hline AM: $n$-hexane & f3 & 0 & 2.92 & 1.94 & & 14.00 \\
\hline \multirow{3}{*}{ PM: $n$-hexane +200 ppm MEK } & $\mathrm{m} 2$ & 0 & 2.70 & 1.85 & 8.84 & 7.00 \\
\hline & $\mathrm{m} 1$ & 0 & 2.39 & 1.47 & 6.13 & 13.00 \\
\hline & $\mathrm{m} 9$ & 0 & 1.84 & 1.25 & 4.90 & 10.00 \\
\hline Group 3 & m3 & 0 & 2.43 & 1.45 & 7.10 & 6.00 \\
\hline AM: $n$-hexane & $\mathrm{m} 4$ & 0 & 2.78 & 1.07 & 7.10 & 8.50 \\
\hline \multirow[t]{3}{*}{ PM: $n$-hexane +300 ppm MEK } & m5 & 0 & 2.90 & 1.83 & 8.61 & 12.50 \\
\hline & m6 & 0 & 2.75 & 1.55 & 6.94 & 12.00 \\
\hline & $\mathrm{m} 18$ & 0 & 2.51 & 1.58 & 9.40 & 6.00 \\
\hline Group 4 & f2 & 300 & 2.94 & 1.90 & 6.00 & 8.00 \\
\hline AM: $n$-hexane +300 ppm MEK & m15 & 300 & 2.85 & 1.84 & 8.74 & 13.00 \\
\hline \multirow{2}{*}{ PM: $n$-hexane } & m16 & 300 & 2.50 & 1.36 & 7.58 & 11.00 \\
\hline & m17 & 300 & 2.70 & 1.64 & 8.35 & 11.50 \\
\hline
\end{tabular}

Note. For each individual, $n$-hexane concentrations (concentration inhaled, $C_{\mathrm{I}}$; and concentration exhaled, $C_{\mathrm{e}}$ ), breathing minute volume (MV), and breathing frequency $(f)$ are reported.

TABLE 1b

Individual Exposure Conditions Regarding the Second Exposure (PM) to $n$-Hexane Alone or in Combination with MEK

\begin{tabular}{|c|c|c|c|c|c|c|c|}
\hline \multirow[b]{2}{*}{ Second exposure (PM) } & \multirow[b]{2}{*}{ Subject } & \multirow{2}{*}{$\begin{array}{l}\text { MEK } \\
(\mathrm{ppm})\end{array}$} & \multirow{2}{*}{$\begin{array}{c}\text { Time } 2 \text { nd } \\
\text { exposure } \\
\text { (hr) }\end{array}$} & \multicolumn{2}{|c|}{ Hexane $(\mu \mathrm{M})$} & \multirow{2}{*}{$\begin{array}{c}\text { MV } \\
\text { (liters/min) }\end{array}$} & \multirow{2}{*}{$\begin{array}{c}f \\
\left(\min ^{-1}\right)\end{array}$} \\
\hline & & & & $\mathrm{c}_{\mathrm{I}}$ & $\mathrm{c}_{\mathrm{e}}$ & & \\
\hline Group 1 & $\mathrm{~m} 10$ & 0 & 3.83 & 2.16 & 1.37 & 6.32 & 11.50 \\
\hline AM: $n$-hexane & $\mathrm{m} 12$ & 0 & 4.00 & 2.70 & 1.77 & 9.84 & 12.00 \\
\hline \multirow[t]{3}{*}{ PM: $n$-hexane } & $\mathrm{m} 13$ & 0 & 4.03 & 2.54 & 1.98 & 7.67 & 17.00 \\
\hline & $\mathrm{m} 14$ & 0 & 4.05 & 2.38 & 1.45 & 7.35 & 11.00 \\
\hline & $\mathrm{m} 11$ & 0 & 3.63 & 3.11 & 1.81 & 7.03 & 10.00 \\
\hline Group 2 & f1 & 200 & 4.00 & 2.56 & 1.55 & 6.58 & 17.00 \\
\hline AM: $n$-hexane & f3 & 200 & 4.18 & 2.78 & 2.19 & 6.60 & 14.00 \\
\hline \multirow[t]{3}{*}{ PM: $n$-hexane +200 ppm MEK } & $\mathrm{m} 2$ & 200 & 4.13 & 2.81 & 1.91 & 8.32 & 7.00 \\
\hline & $\mathrm{m} 1$ & 200 & 4.17 & 2.49 & & 6.52 & 13.00 \\
\hline & $\mathrm{m} 9$ & 200 & 3.83 & 1.86 & 1.14 & 6.13 & 10.00 \\
\hline Group 3 & $\mathrm{~m} 3$ & 300 & 3.88 & 2.67 & 1.76 & 8.65 & 6.00 \\
\hline AM: $n$-hexane & $\mathrm{m} 4$ & 300 & 3.87 & 2.82 & 1.26 & 7.10 & 8.50 \\
\hline \multirow[t]{3}{*}{ PM: $n$-hexane +300 ppm MEK } & $\mathrm{m} 5$ & 300 & 3.83 & 2.96 & 1.93 & 8.45 & 13.00 \\
\hline & $\mathrm{m} 6$ & 300 & 3.87 & 2.61 & 1.51 & 7.10 & 11.00 \\
\hline & $\mathrm{m} 18$ & 300 & 4.00 & 2.50 & 1.66 & 10.80 & 8.00 \\
\hline Group 4 & $\mathrm{f} 2$ & 0 & 3.68 & 3.17 & 1.94 & 6.52 & 8.00 \\
\hline AM: $n$-hexane +300 ppm MEK & $\mathrm{m} 15$ & 0 & 4.02 & 2.62 & 1.77 & 8.03 & 13.00 \\
\hline \multirow[t]{2}{*}{ PM: $n$-hexane } & $\mathrm{m} 16$ & 0 & 4.03 & 2.53 & 1.51 & 8.06 & 11.00 \\
\hline & $\mathrm{m} 17$ & 0 & 4.00 & 2.86 & 1.72 & 8.77 & 11.50 \\
\hline
\end{tabular}

Note. For each individual, $n$-hexane concentrations (concentration inhaled, $C_{\mathrm{I}}$; and concentration exhaled, $C_{\mathrm{e}}$ ), breathing minute volume (MV), and breathing frequency $(f)$ are reported. 
Instrument Development Inc., Avondale, PA) with capillary diffusion tubes at constant temperature. Subsequently, $n$-hexane was diluted to the appropriate concentrations with air, collected in a 70-ml glass tube, and analyzed.

$\boldsymbol{G C}$ conditions. In order to separate the MEK peak from the $n$-hexane peak, two capillary columns were used, connected by a glass connector. The first was a cross-linked methyl siloxane column (HP1, Hewlett Packard) $25 \mathrm{~m} \times 0.2 \mathrm{~mm}$, film thickness $0.11 \mu \mathrm{m}$. The second column was a WCOT fused silica (CPsil43CB, Chrompack, Middelburg, The Netherlands). The head pressure used was $85 \mathrm{kPa}$. After injection by the purge and trap system, the oven temperature was $35^{\circ} \mathrm{C}$ and was increased after $4.5 \mathrm{~min}$ at a rate of $70^{\circ} \mathrm{C} / \mathrm{min}$ to $100^{\circ} \mathrm{C}$. The retention times were 3.9 and $4.4 \mathrm{~min}$ for $n$ hexane and MEK, respectively.

Determination of 2,5-hexanedione. Serum was analyzed for 2,5-hexanedione according to Kežić and Monster (1991), with the following slight modification (Van Engelen et al., 1995a). A 100- $\mu$ l sample of 0.33 M sodium citrate buffer, $\mathrm{pH} 2.2$, was mixed with $400 \mu \mathrm{l}$ serum. As internal standard, $50 \mu \mathrm{l}$ of a $4.9 \mu \mathrm{M}$ solution of 2,4-pentanedione was added, as well as 50 $\mu \mathrm{l}$ of a $20 \mathrm{mg} / \mathrm{ml}$ aqueous solution of the derivatization agent $O-(2,3,4,5,6$ pentafluorobenzyl)hydroxylamine (PFBHA). Standard samples were prepared by adding $0-200 \mu \mathrm{l}$ of $3.3 \mu \mathrm{M}$ aqueous solution of 2,5-hexanedione to blank serum samples from the same volunteer. The reaction was allowed to proceed for at least $16 \mathrm{hr}$ at room temperature; $300 \mu \mathrm{l}$ cyclohexane was added and samples were left rotating for $90 \mathrm{~min}$. The samples were centrifuged for $10 \mathrm{~min}$ (Eppendorf centrifuge, $3000 \mathrm{~g}$ ) and $1 \mu \mathrm{l}$ of the cyclohexane extract was injected onto the GC column.

\section{RESULTS}

\section{A. Toxicokinetics of n-Hexane in Exhaled Air}

The time course of the $n$-hexane concentration in exhaled alveolar air was determined after alveolar air sampling with a breath-holding time of $30 \mathrm{sec}$. Under these conditions, the alveolar concentration is considered to be in equilibrium with the mixed venous blood entering the lungs $\left(C_{\text {ven }}\right)$ (see the Appendix). Several parameters for the kinetics of $n$ hexane have been determined: the area under the $n$-hexane concentration-time curve during and after exposure (A1 and $\mathrm{A} 2$, respectively) and the functional alveolar ventilation rate $\left(V_{\mathrm{a}}\right)$ (for calculation of these parameters see the Appendix). $\mathrm{A} 1$ and $\mathrm{A} 2$ were normalized to functional intake $\left(C_{\mathrm{I}} V_{\mathrm{a}} t_{1}\right)$ (Opdam, 1989).

Exposure to $n$-hexane alone, both in the morning (AM) and in the afternoon (PM), served as a control experiment. Little variation in the toxicokinetics of $n$-hexane (and 2,5hexanedione) between the morning and the afternoon exposures within the same subject was observed, as is confirmed by the results of group 1 (Table 2).

To assess the effect of MEK on the toxicokinetics of $n$-hexane, the ratio for each parameter was expressed as coexposure relative to single solvent exposure.

In the first set of coexposure experiments, volunteers were exposed to $200 \mathrm{ppm}$ MEK in the afternoon (group 2). There was very little, if any, effect of MEK on the concentrationtime courses of $n$-hexane and 2,5-hexanedione. Therefore, the MEK concentration was increased to $300 \mathrm{ppm}$ (group 3 ). The order of coexposure and exposure to $n$-hexane alone was also changed to examine whether coexposure in the
TABLE 2

Toxicokinetic Parameters of $n$-H exane, Presented as a Ratio: Coexposure to $n$-H exane + MEK R elative to Exposure to $n$-H exane Alone

\begin{tabular}{lccc}
\hline & A1 & A2 & $V_{\text {a }}$ \\
\hline Group $1 ; n=5$ & & & \\
AM: $n$-hexane & $1.00(0.04)$ & $1.01(0.18)$ & $0.92(0.07)$ \\
PM: $n$-hexane & & \\
Group $2 ; n=5$ & $0.98(0.05)$ & $1.07(0.16)$ & $1.05(0.15)$ \\
AM: $n$-hexane & & & \\
PM: $n$-hexane $+200 \mathrm{ppm}$ & & \\
$\quad$ MEK & & & \\
Group $3 ; n=4$ & & \\
AM: $n$-hexane & & & \\
PM: $n$-hexane $+300 \mathrm{ppm}$ & & & \\
$\quad$ MEK & & & \\
Group $4 ; n=4$ & & & \\
AM: $n$-hexane $+300 \mathrm{ppm}$ & & & \\
$\quad$ MEK & & & \\
PM: $n$-hexane & & & \\
\hline
\end{tabular}

Note. Areas A1 (during exposure) and A2 (after exposure) were normalized to functional intake. $V_{\mathrm{a}}$, functional alveolar ventilation rate. Values given are mean ratios of $n$ volunteers; standard deviations are shown in parentheses. For group 1 (exposure to $n$-hexane as single solvent in the morning (AM) and in the afternoon (PM)) the ratio was expressed as AM value relative to the PM value. Due to an experimental error no information on the concentration of $n$-hexane in alveolar air is available for one volunteer (m18, group 3). As a result the parameters $\mathrm{A} 1, \mathrm{~A} 2$, and $V_{\mathrm{a}}$ could be calculated only for $n=4$.

morning (AM) influences the afternoon exposure to $n$-hexane alone.

Coexposure to MEK did not significantly alter the kinetic parameters for $n$-hexane (Table 2).

\section{B. Toxicokinetics of 2,5-Hexanedione in Blood}

During and after exposure, blood was sampled and the serum was analyzed for the concentration of 2,5-hexanedione. Contrary to the lack of effect of MEK on the kinetic parameters of $n$-hexane, the formation of 2,5-hexanedione was severely affected: the concentration-time course of 2,5hexanedione after coexposure to 300 ppm MEK was different from that obtained after exposure to $n$-hexane alone. Coexposure to the lower concentration of MEK (200 ppm), however, had no effect (Table 3).

A typical example of the concentration-time course of 2,5-hexanedione, measured in serum obtained from a volunteer exposed for $15.5 \mathrm{~min}$ to $n$-hexane alone both in the morning (at $t=0$ ) and $4 \mathrm{hr}$ later, in the afternoon (group 1 ), is shown in Fig. 2a. These two time courses look very similar. Figure $2 \mathrm{~b}$ presents a typical concentration-time course of 2,5-hexanedione after exposure to $n$-hexane alone in the morning and to a mixture of $n$-hexane and MEK in the afternoon (group 3). There is a marked difference be- 
TABLE 3

Rate of Appearance (Slope) of 2,5-H exanedione in Serum

\begin{tabular}{|c|c|c|c|c|c|}
\hline & Subject & $\begin{array}{c}\text { Slope AM } \\
(\mu \mathrm{M} / \mathrm{hr})\end{array}$ & $\begin{array}{c}\text { Slope PM } \\
(\mu \mathrm{M} / \mathrm{hr})\end{array}$ & Ratio & Mean ratio (sd) \\
\hline & & & & hex/hex & \multirow{7}{*}{$1.03(0.27)$} \\
\hline Group 1 & $\mathrm{~m} 10$ & 2.88 & 4.15 & 0.69 & \\
\hline AM: $n$-hexane & $\mathrm{m} 12$ & 4.48 & 4.43 & 1.01 & \\
\hline \multirow{4}{*}{ PM: $n$-hexane } & $\mathrm{m} 13$ & 3.83 & 2.81 & 1.36 & \\
\hline & $\mathrm{m} 14$ & 3.94 & 3.16 & 1.25 & \\
\hline & \multirow[t]{2}{*}{$\mathrm{m} 11$} & \multirow[t]{2}{*}{4.05} & \multirow[t]{2}{*}{4.69} & 0.86 & \\
\hline & & & & MEK/hex & \\
\hline Group 2 & f1 & 3.32 & 2.73 & 0.82 & \\
\hline AM: $n$-hexane & $\mathrm{f} 3$ & 1.97 & 1.22 & 0.62 & \multirow{5}{*}{$0.99(0.30)$} \\
\hline \multirow[t]{4}{*}{ PM: $n$-hexane +200 ppm MEK } & $\mathrm{m} 2$ & 3.01 & 2.84 & 0.94 & \\
\hline & $\mathrm{m} 1$ & 1.85 & 2.57 & 1.39 & \\
\hline & \multirow[t]{2}{*}{$\mathrm{m} 9$} & \multirow[t]{2}{*}{3.31} & \multirow[t]{2}{*}{3.84} & 1.16 & \\
\hline & & & & MEK/hex & \\
\hline Group 3 & $\mathrm{~m} 3$ & 1.89 & 0.75 & 0.40 & \multirow{6}{*}{$0.35(0.16)^{*}$} \\
\hline AM: $n$-hexane & $\mathrm{m} 4$ & 2.48 & 1.44 & 0.58 & \\
\hline \multirow[t]{4}{*}{ PM: $n$-hexane +300 ppm MEK } & $\mathrm{m} 5$ & 3.92 & 0.94 & 0.24 & \\
\hline & $\mathrm{m} 6$ & 2.46 & 0.88 & 0.36 & \\
\hline & \multirow[t]{2}{*}{$\mathrm{m} 18$} & \multirow[t]{2}{*}{4.23} & \multirow[t]{2}{*}{0.72} & 0.17 & \\
\hline & & & & MEK/hex & \\
\hline Group 4 & f2 & 1.73 & 5.38 & 0.32 & \\
\hline AM: $n$-hexane $+300 \mathrm{ppm}$ MEK & $\mathrm{m} 15$ & 3.04 & 4.01 & 0.76 & \\
\hline PM: $n$-hexane & $\mathrm{m} 16$ & 2.28 & 5.61 & 0.41 & $0.46(0.21)^{* *}$ \\
\hline & $\mathrm{m} 17$ & 1.38 & 4.15 & 0.33 & \\
\hline
\end{tabular}

Note. Slopes are expressed as a ratio (coexposure relative to slope after exposure to $n$-hexane alone). For group 1 (exposure to $n$-hexane as single solvent in the morning (AM) and in the afternoon (PM)) the ratio was expressed as AM value relative to the PM value.

* Significantly different from control $(p<0.001)$ (Student's $t$ test).

** Significantly different from control $(p<0.05)$ (Student's $t$ test).

tween the curves obtained following mixed exposure and exposure to $n$-hexane alone; the peak concentration was lower and the time required to reach this peak increased. This is shown in more detail in Fig. 3.

To characterize the shape of the first part of the curve quantitatively, two parameters were determined: its slope and $T_{\max }$. The first parameter, slope, was calculated by linear regression analysis of the concentration-time course during exposure; it indicates the rate at which 2,5-hexanedione appears in the blood $(\mu \mathrm{M} / \mathrm{hr})$. The second parameter, $T_{\max }$, is the time required for 2,5-hexanedione to reach a maximum serum concentration value. The two parameters are visually explained in Fig. 3. The slopes are presented in Table 3 again as a ratio (slope after coexposure relative to slope after exposure to $n$-hexane alone). Ratios of $T_{\max }$ are presented in Fig. 4. Subjects that were exposed to $n$-hexane as a single solvent during both the first and the second exposures (group 1) have values for the ratio of the slopes that are close to unity: the mean value of the ratio (first exposure (AM) relative to the second exposure (PM)) is 1.03 (Table 3). The time to reach maximum concentration, $T_{\max }$, varied between 16.2 and $19.8 \mathrm{~min}$; there was no difference in $T_{\max }$ between the morning (AM) and the afternoon (PM) exposures (Fig. 4). As the duration of the exposure was $15 \mathrm{~min}$, the maximum concentration is reached 1 to 4 min after cessation of the exposure.

Two groups of volunteers were exposed to a combination of $n$-hexane and MEK in the afternoon: one group was exposed to a MEK concentration of $200 \mathrm{ppm}$ (group 2 ), the other to a concentration of $300 \mathrm{ppm}$ (group 3). The individual exposure concentrations of $n$-hexane are presented in Table 1. In group 2 no decrease in slope due to the combined exposure could be observed; the mean ratio of slopes was 0.99 . In this group, there is a trend to higher values of $T_{\max }$ on mixed exposure compared to that seen with single $n$-hexane exposure (24.4 versus 20.4 min). The effect of MEK coexposure on the slope is evident, however, in group 3, where volunteers were exposed to an MEK concentration of $300 \mathrm{ppm}$ in the afternoon. The slope in the case of mixed exposure was about threefold lower than obtained on exposure to $n$-hexane alone: a mean value of 0.35 . The effect on $T_{\max }$ was also more pronounced; the mean time to maximum concentration increased from $19.4 \mathrm{~min}$ after single solvent exposure 

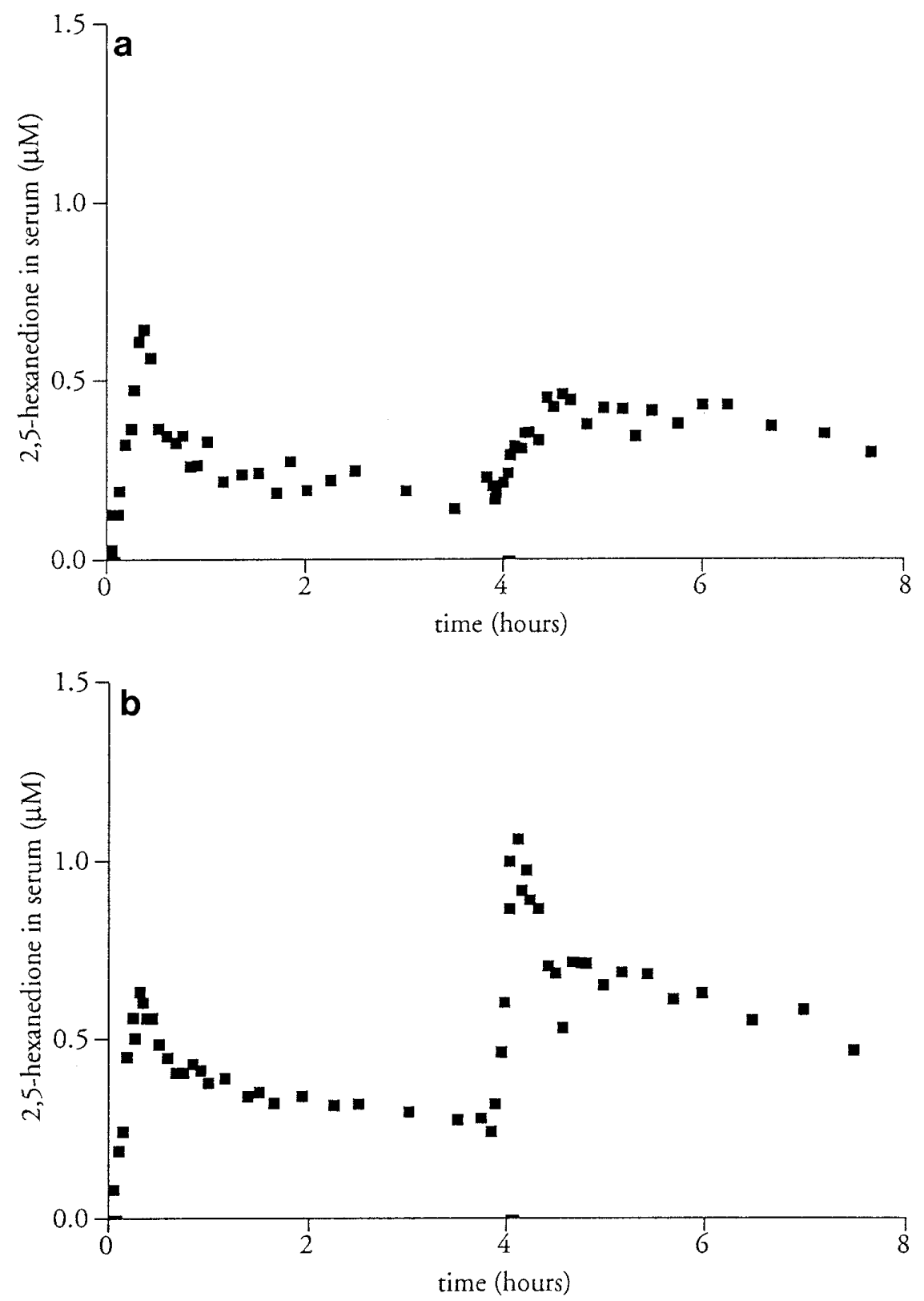

FIG. 2. Effect of MEK on 2,5-hexanedione in serum after exposure to $n$-hexane. (a) Serum concentration-time course of 2,5-hexanedione in subject $\mathrm{m} 10$; this subject was exposed twice (AM and PM) to $n$-hexane. The bar on the $x$-axis indicates the period of exposure. (b) Serum concentration-time course of 2,5-hexanedione in subject m3; this subject was exposed to $n$-hexane (AM) and to $n$-hexane plus 300 ppm MEK (PM). The bar on the $x$-axis indicates the period of exposure.

(AM) to 31.6 min after combined exposure (PM). In another set of experiments, volunteers were first exposed (AM) to $n$-hexane and MEK (300 ppm) and $4 \mathrm{hr}$ later (PM) to $n$-hexane alone (group 4). The effects of MEK coexposure on the slope are again evident: the ratios have a mean value of 0.46 . $T_{\max }$ also seemed to increase as compared to the control situation, although less than in group 3; this increase is not statistically significant (Table 3; Fig. 4).

\section{Kinetic Modeling}

Kinetic modeling may be useful to simulate the effect of a second compound on the time course of 2,5-hexanedione. The entire kinetic process from $n$-hexane intake during exposure, via the $n$-hexane blood concentration, the formation and concentration of intermediate metabolite(s) (M), the formation of 2,5-hexanedione, and finally the 2,5-hexanedione blood concentration can be considered as a cascade of con- 


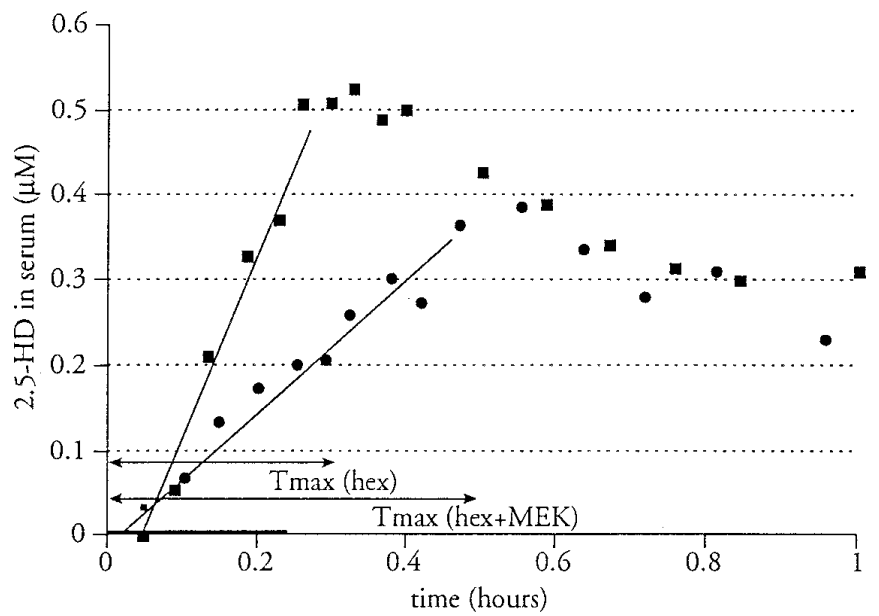

FIG. 3. Serum concentration of 2,5-hexanedione obtained from a subject exposed to $n$-hexane alone (squares) or coexposed to $300 \mathrm{ppm}$ MEK (circles). The slopes and $T_{\max }$ are indicated. The bar on the $x$-axis denotes the period of exposure.

nected kinetic systems (Opdam, 1991). Inhibition of the conversion of the intermediate metabolite to 2,5-hexanedione can be simulated by lowering the metabolic clearance of $\mathrm{M}$. As a result, the half-time of $\mathrm{M}$ increases and the rate of formation of 2,5-hexanedione (i.e., clearance $\times$ blood concentration of M) becomes relatively low. In Fig. 5, inhibition by MEK is simulated by a fourfold lowering of the metabolic clearance of M. As a result, the slope of 2,5-hexanedione decreases and $T_{\max }$ increases.

\section{DISCUSSION}

The present volunteer study reveals an effect of MEK coexposure on $n$-hexane biotransformation, after short-term (15.5 min) exposure to relatively low concentrations. The fast kinetics of $n$-hexane and 2,5-hexanedione could be accurately studied, as blood and alveolar air were sampled frequently. In addition, sensitive analytical procedures were applied, so that small changes in concentration could be identified. To the best of our knowledge, the effects of MEK on the kinetics of $n$-hexane have not been studied in a laboratory setting using volunteers before.

Very little, if any, effect of coexposure to MEK was observed on the toxicokinetic parameters of $n$-hexane itself (Table 3). It is evident, however, that there is an effect of MEK on the rate of metabolism of $n$-hexane to 2,5-hexanedione. If the volunteers are exposed only to $n$-hexane, there is only a small variation between the 2,5-hexanedione concentration-time courses, if the first (AM) and second (PM) exposures are compared. However, after coexposure the time courses are different from those obtained after exposure to $n$-hexane alone: the 2,5-hexanedione peak remains below the control value and seems to be cut off.
MEK has a pronounced, dose-dependent effect on the rate with which 2,5-hexanedione appears in the blood: coexposure to $300 \mathrm{ppm}$ MEK caused a decrease in slope, whereas exposure to $200 \mathrm{ppm}$ MEK caused no change compared with the control value; $T_{\max }$, however, appeared to increase also after coexposure to only $200 \mathrm{ppm}$ MEK. Coexposure to 300 ppm MEK in the first (AM) or second (PM) period (groups 3 and 4) had the same effect: for both groups, slopes decreased to a similar extent, compared with exposure to $n$ hexane alone. The effect of coexposure on $T_{\max }$ was, however, less pronounced in group 4 than in group 3. Since we cannot exactly define at which step MEK and $n$-hexane interact we cannot explain this dose-dependency of MEK; it may be due to a metabolite of $n$-hexane, formation of which, to the required level for interaction, may be strongly dose-dependent.

Theoretically, 2,5-hexanedione levels could both have been increased or decreased following coexposure to $n$-hexane and MEK. For instance, a biotransformation pathway leading to nonneurotoxic metabolites of $n$-hexane could have been inhibited, thereby increasing the concentration of 2,5hexanedione. However, animal studies had already suggested that after short-term coexposure to MEK and $n$-hexane the concentration of 2,5-hexanedione in blood was decreased in comparison with exposure to $n$-hexane alone: rats exposed for $8 \mathrm{hr}$ to the very high level of $2000 \mathrm{ppm} n$ hexane alone or in combination with 2000 ppm MEK were studied by Shibata et al. (1990). If exposed to $n$-hexane alone, 2,5-hexanedione in serum increased until $2 \mathrm{hr}$ after termination of exposure to a peak concentration of $143 \mu \mathrm{M}$. After coexposure, however, the peak concentration of 2,5hexanedione was only $18.6 \mu \mathrm{M}$, which was reached $8 \mathrm{hr}$

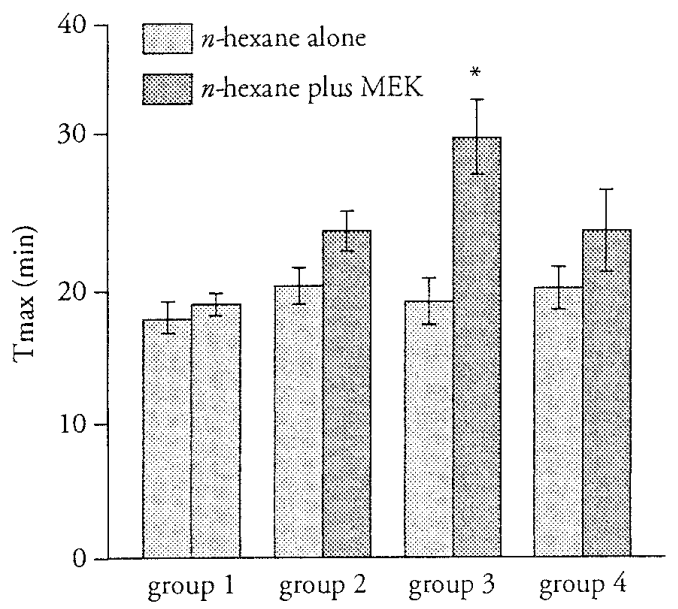

FIG. 4. Effects of MEK on the time required to reach a maximum for the 2,5-hexanedione concentration in serum. The MEK-concentrations were $0,200,300$, and $300 \mathrm{ppm}$ for groups 1, 2, 3, and 4, respectively. Values presented are mean $\pm \mathrm{SD}$ (for group 1,2 , and $3, n=5$; group $4, n=$ 4). *Significantly different from control $(=n$-hexane alone $)(p<0.001)$ (Student's $t$ test). 


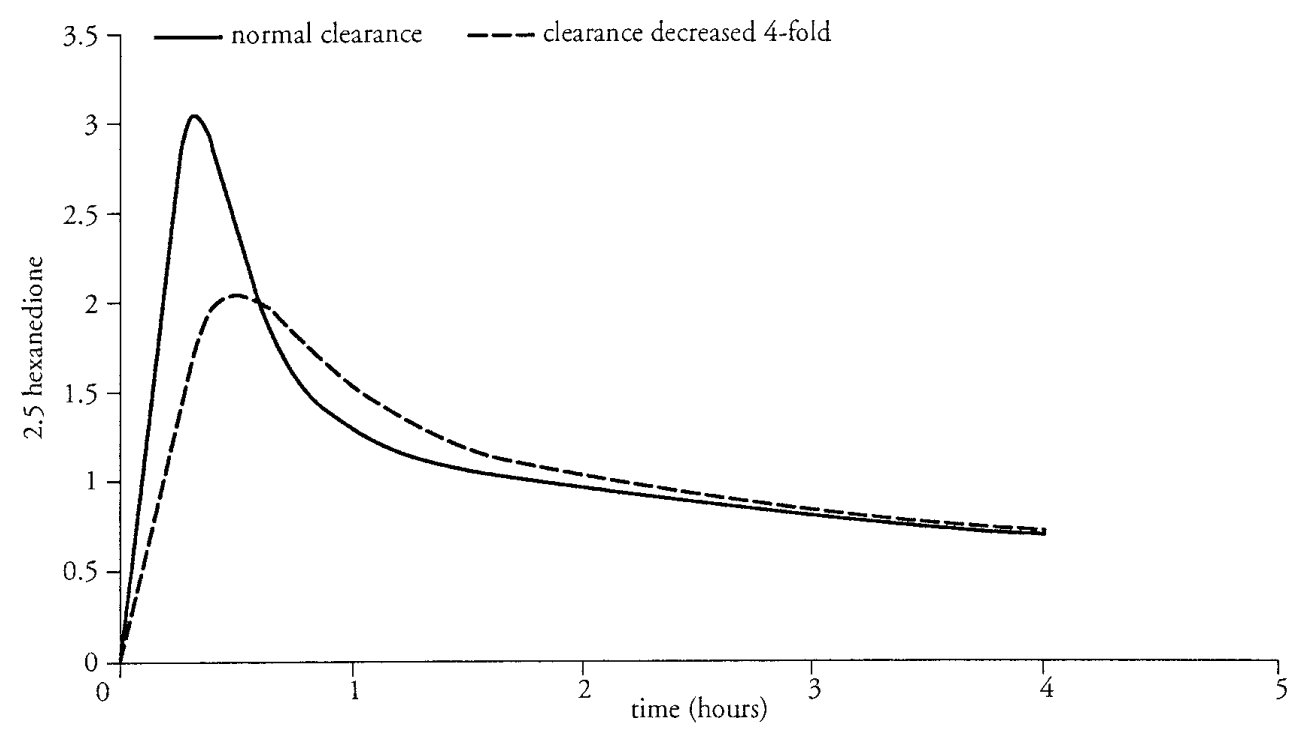

FIG. 5. Simulation of the concentration-time course of 2,5-hexanedione after coexposure to $n$-hexane and MEK ( $\cdots)$ or after exposure to $n$-hexane alone $(-)$.

after termination of exposure. As the levels of exposure are extremely high compared to the occupational situation, these results could not be simply extrapolated to the volunteer setting (dose-dose extrapolation and species-species extrapolation). Yet, in the present study, using low concentrations, the same effect was observed, confirming its relevance for the occupational setting.

$n$-Hexane metabolism to 2,5-hexanedione requires several intermediate steps (Fig. 6). MEK could possibly inhibit each

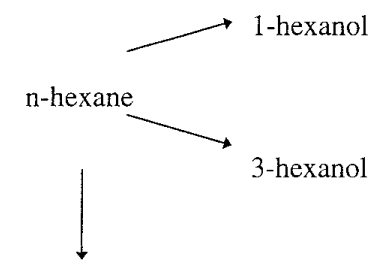

-valerolactone

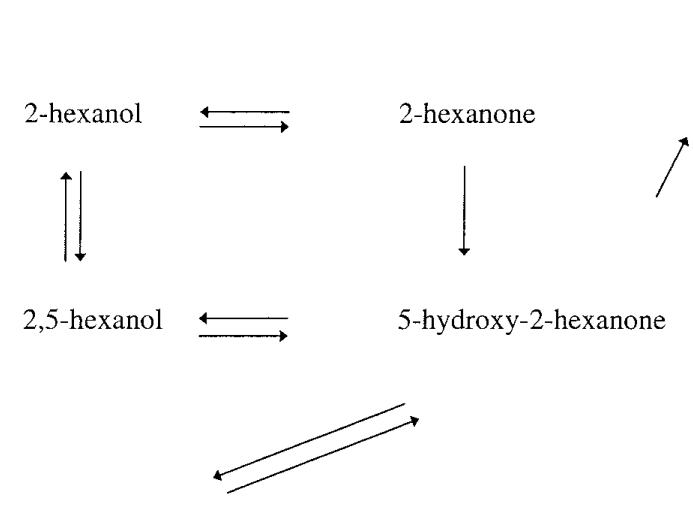

2,5-hexanedione $\longrightarrow$ 4,5-dihydroxy-2-hexanone

FIG 6. Biotransformation of $n$-hexane to 2,5-hexanedione. of these steps: given the structural similarity between MEK (2-butanone) and 2-hexanone, it is plausible that MEK competes with 2-hexanone for the substrate binding site of the various enzymes involved in these steps. The decrease in slope and the prolongation of formation of 2,5-hexanedione in combination with the apparently unchanged $n$-hexane elimination, suggests an accumulation of an intermediate precursor of 2,5-hexanedione. After cessation of exposure, this accumulated metabolite will then be slowly converted to 2,5-hexanedione.

The kinetic simulation (Fig. 5) gives support to the suggestion that the changes observed during the time course of 2,5hexanedione may be caused by an inhibition of the metabolic conversion of an intermediate metabolite to 2,5-hexanedione. There is no need to postulate either any effect on the time course of $n$-hexane itself or any changes in the elimination kinetics of 2,5-hexanedione metabolism after its formation. Nevertheless, the tentative model described does not exclude other alterations in the kinetics of the drug metabolism process from $n$-hexane intake to 2,5 -hexanedione formation.

Shibata et al. (1990) reported a decrease in the concentration of 2-hexanone in serum following high-dose coexposure in the rat. The toxicokinetics of this metabolite were changed, however, as the half-life of 2-hexanone in the coexposure group was twice as long as that in the $n$-hexane alone group.

In the present study, we were not able to detect 2-hexanone in the serum of volunteers, possibly due to a lack of sensitivity of our analytical method. The concentrations of $n$-hexane and MEK to which the volunteers were exposed were very low in comparison with the rat studies of Shibata 
et al. (1990). Thus, it remains to be seen whether the mechanism at high doses in the rat may be extrapolated to that at low doses in man. Recent studies in the rat in our laboratory using exposure levels similar to those given to our volunteers confirmed that the effects observed in the volunteers are very similar to those observed in rats (both using the same concentration levels and exposure-duration times) (Van Engelen, 1995b; Van Engelen et al., in preparation).

An interaction during short-term coexposure to $n$-hexane and MEK can be very different from that produced upon chronic coexposure (Shibata et al., 1990). Thus, Robertson et al. (1989) found elevated levels of 2,5-hexanedione (approx. eightfold) in blood of rats after 4 days of pretreatment with MEK (1.87 ml/kg/day, by gavage), followed by a single inhalation exposure to $n$-hexane (1000 ppm). After these 4 days of MEK administration, the activity of 7-ethoxycoumarin- $O$-deethylase was increased by up to $500 \%$, most probably due to enzyme induction. Obviously, during short-term coexposure (15 min to a low concentration in our experiments), MEK will not induce the biotransformation enzymes involved in $n$-hexane metabolism. However, it may inhibit the biotransformation from $n$-hexane to 2,5-hexanedione.

If during chronic coexposure to MEK and $n$-hexane induction of biotransformation enzymes by MEK plays a role, then the design of the volunteer experiments reported here cannot be used to predict the effects produced in occupational settings in which workers may be exposed to the mixture chronically. The direct interaction between the two solvents as discussed above, will also occur during chronic exposure at occupationally relevant concentrations, in addition to eventual inducting effects of MEK. It seems likely that the mechanisms of interaction are similar to those occurring in rats. In humans, the potentiation of neurotoxicity by MEK is most probably not caused by inhibition of one of the pathways leading to nontoxic metabolites of $n$ hexane, but rather by enzyme induction to form more 2,5hexanedione.

\section{APPENDIX: TOXICOKINETIC ANALYSIS OF $n$-HEXANE IN ALVEOLAR AIR}

During normal breathing, during and after exposure, $n$ hexane is transported through the lungs to the blood as is presented schematically in Fig. 7. $n$-Hexane is exchanged between the alveolar air and the (pulmonary) blood compartment.

The volunteer inhales air with a $n$-hexane concentration of $C_{\mathrm{I}}$ and exhales air with a concentration of $C_{\mathrm{e}}$. The difference between $C_{\mathrm{I}}$ and $C_{\mathrm{e}}$ multiplied by the breathing minute volume (MV) and the duration of exposure $\left(t_{1}\right)$ results in the amount that remained in the body (net uptake). This amount is equal to the amount taken up by the blood compartment minus the amount eliminated from the blood into the lungs.

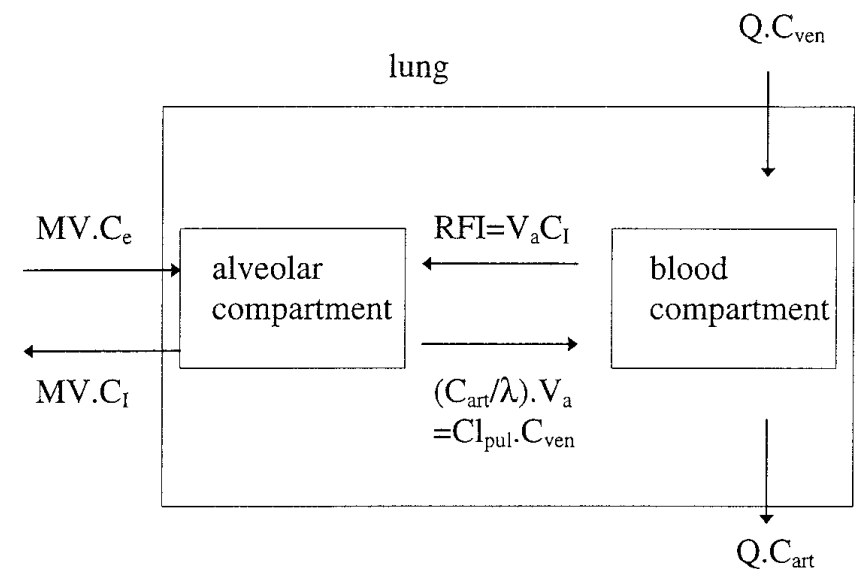

FIG. 7. Schematic overview of the toxicokinetics of gas exchange in the lungs. The lungs are represented as an alveolar air and a pulmonary blood compartment. Net uptake is the difference in concentration between the inhaled and exhaled air ( $C_{1}$ and $C_{\mathrm{e}}$, respectively), multiplied by the minute volume (MV). The rate of functional intake (RFI) is equal to $V_{\mathrm{a}} C_{\mathrm{I}}$.

During exposure, $n$-hexane (inhaled concentration $C_{\mathrm{I}}$ ) can be transported to the pulmonary blood with a rate equal to the functional alveolar ventilation rate $V_{\mathrm{a}}$. This rate represents the functional alveolar volume per minute that is in equilibrium with the arterial blood leaving the lungs. This volume is smaller than the minute breathing volume, as it only takes into consideration that part of the lungs which is able to exchange with blood ("functional volume") and does not include the anatomical and functionally dead volume. $n$ Hexane is also eliminated by the blood to the lungs, with a rate of $V_{\mathrm{a}}$, with a concentration of $C_{\text {art }} / \lambda$. In the case of $n$ hexane, $\lambda$ has a value of 0.8 . The term, $V_{\mathrm{a}} \times C_{\mathrm{art}} / \lambda$, is equal to the product of the pulmonary clearance and the concentration in mixed venous blood: $\mathrm{Cl}_{\text {pul }} \times C_{\text {ven }}$ (see below).

In blood, the amount of $n$-hexane leaving the lung is equal to the concentration in arterial blood $\left(C_{\text {art }}\right)$ multiplied by the cardiac output $Q$; the amount of $n$-hexane in the returning mixed venous blood is equal to the concentration in mixed venous blood, $C_{\text {ven }}$, multiplied by $Q$. During exposure, $C_{\text {ven }}$ is lower than $C_{\text {art }}$, due to distribution and metabolic processes in the body.

All processes presented in Fig. 7 can be described using two equations:

For the alveolar air compartment,

$$
\operatorname{MV}\left(C_{\mathrm{I}}-C_{\mathrm{e}}\right)=V_{\mathrm{a}}\left(C_{\mathrm{I}}-C_{\mathrm{art}} / \lambda\right)
$$

For the pulmonary blood compartment,

$$
C_{\mathrm{I}} V_{\mathrm{a}}+Q C_{\mathrm{ven}}=C_{\mathrm{art}} V_{\mathrm{a}}+Q C_{\mathrm{art}} .
$$

The rate of elimination from the blood to the alveolar compartment is considered to be a continuous process both 
during and after exposure (Opdam, 1989). The rate of pulmonary excretion $\mathrm{RE}_{\text {pul }}$ is equal to the product of the pulmonary clearance $\left(\mathrm{Cl}_{\mathrm{pul}}\right)$ and the concentration of $n$-hexane in venous blood $\left(C_{\text {ven }}\right)$ :

$$
\mathrm{RE}_{\mathrm{pul}}=\mathrm{Cl}_{\mathrm{pul}} \times C_{\mathrm{ven}} .
$$

After exposure, $C_{\mathrm{I}}=0$ and $\left.\mathrm{Cl}_{\mathrm{pul}}=Q\left(C_{\mathrm{ven}}-C_{\mathrm{art}}\right) / C_{\mathrm{ven}}\right)$; combined with Eq. (1) the pulmonary clearance $\left(\mathrm{Cl}_{\mathrm{pul}}\right)$ is written as

$$
\mathrm{Cl}_{\mathrm{pul}}=\frac{Q\left(C_{\mathrm{ven}}-C_{\mathrm{art}}\right)}{C_{\mathrm{ven}}}
$$

In order to estimate the functional alveolar ventilation $V_{\mathrm{a}}$, the integral of Eq. (1) in combination with Eq. (4) describes the total uptake:

$$
U_{\text {tot }}=\left(C_{\mathrm{I}}-C_{\mathrm{e}}\right) \mathrm{MV} t_{1}=C_{\mathrm{I}}-V_{\mathrm{a}} t_{1}-\mathrm{Cl}_{\mathrm{pul}} \int_{0}^{t_{1}} C_{\mathrm{ven}} d t .
$$

Obviously, in the volunteer studies, $C_{\text {ven }}, C_{\text {art }}$, and $V_{\text {a }}$ cannot be measured directly. However, it can be calculated (Opdam and Smolders, 1986) that after holding the breath for $30 \mathrm{sec}$, the concentration in the alveolar air approaches the $C_{\text {ven }}$. During exposure, $C_{\text {ven }}$ is overestimated by $15-20 \%$; after exposure, there will be an underestimation of 5-10\%. In our calculations, however, we consider the air sampled after breath-holding to be in equilibrium with $C_{\text {ven }}$ (see also Discussion). The concentration of $n$-hexane in alveolar air after $30 \mathrm{sec}$ of breath holding is denoted by $C_{\text {alv,eq }}$. The concentration-time course of $n$-hexane in venous blood is equal to the concentration-time course of $C_{\text {alv,eq }}$ multiplied by $\lambda$; the same holds for the area under the curve.

\section{Area under the $C_{a l v e q}$ Curve during (A1) and after (A2) Exposure}

During and after exposure the observed $C_{\text {alv,eq }}$ data were fitted using Eqs. (4a) and (4b), respectively, by means of minimizing the weighted sums of squared deviations, using a sequential simplex procedure (Nelder and Mead, 1965), resulting in estimates for $c(\mathrm{i})$ and $r(\mathrm{i})$. The variability of the data around the fitted line was expressed by the weighted residual error (WRE),

$$
\begin{aligned}
& \text { for } t<t_{1}: C_{\mathrm{alv}, \mathrm{eq}}(t)=\sum_{i=1}^{p} c(\mathrm{i})\left(1-e^{r(\mathrm{i}) t}\right) \\
& \text { for } t>t_{1}: C_{\mathrm{alv}, \mathrm{eq}}(t)=\sum_{i=1}^{p} c(\mathrm{i})\left(e^{r(\mathrm{i}) t-t_{1}}-e^{r(\mathrm{i}) t}\right),
\end{aligned}
$$

where $t_{1}$ is end of exposure (min) and $p$ the number of exponential terms $r(\mathrm{i})$ (=neg.) and coefficients $c(\mathrm{i})$;

$$
\mathrm{WRE}=\sqrt{\sum_{i=1}^{n}\left(\left(y_{\mathrm{j}}-\hat{y}_{\mathrm{j}}\right) / \hat{y}_{\mathrm{j}}\right)^{2}} \times 100 \%,
$$

where $y_{\mathrm{j}}$ and $\hat{y}_{\mathrm{j}}$ are the measured and predicted values, respectively.

The areas under $C_{\text {alv,eq }}$ during and after exposure are obtained by integrating Eqs. (6a) and (6b), respectively,

$$
\begin{aligned}
& \mathrm{A} 1=\operatorname{area}\left(C_{\text {alv, eq }}\right) t<t_{1}=\sum_{i=1}^{p} \frac{c(\mathrm{i})}{r(\mathrm{i})}\left(1-e^{r(\mathrm{i}) t_{1}}\right)+c(\mathrm{i}) t_{1} \\
& \mathrm{~A} 2=\operatorname{area}\left(C_{\text {alveq }}\right) t>t_{1}=\sum_{i=1}^{p} \frac{-c(\mathrm{i})}{r(\mathrm{i})}\left(1-e^{r(\mathrm{i}) t_{1}}\right)
\end{aligned}
$$

By combining Eqs. (4) and (5), $V_{\mathrm{a}}$ can be calculated by solving the following quadratic equation and using the experimentally determined $U_{\text {tot }}$ and A1:

$$
V_{\mathrm{a}}=\frac{-b+\sqrt{b^{2}-4 a c}}{2 a},
$$

where $a=1, b=\lambda Q-\lambda A 1 Q /\left(C_{\mathrm{I}} t_{1}\right)-U /\left(C_{\mathrm{I}} t_{1}\right)$, and $c=$ $-U \lambda Q /\left(C_{\mathrm{I}} t_{1}\right)$. The term $C_{\mathrm{I}} V_{\mathrm{a}} t_{1}$ is referred to as total functional intake.

\section{REFERENCES}

Abdel Rahman, M. S., Hetland, L. B., and Couri, D. (1976). Toxicity and metabolism of methyl-n-butyl ketone. Am. Ind. Hyg. Assoc. J. 37, 95101.

Altenkirch, H., Stoltenburg, G., and Wagner, H. M. (1978). Experimental studies on hydrocarbon neuropathies induced by methyl ethyl ketone. $J$. Neurol. 219, 159-170.

Altenkirch, H., Wagner, H. M., Stoltenburg, G., and Spencer, P. S. (1982). Nervous system responses of rats to subchronic inhalation of $n$-hexane and $n$-hexane plus methyl ethyl ketone mixtures. J. Neurol. Sci. 57, 209219.

DeCaprio, A. P. (1987). $n$-Hexane neurotoxicity: A mechanism involving pyrrole adduct formation in axonal cytoskeletal protein. Neurotoxicology 8, 199-210.

Ikeda, M. (1994). Complex exposures: Potentials for assessing integrated exposures. Clin. Chem. 40, 1444-1447.

Ikeda, M. (1995). Exposure to complex mixtures: Implications for biological monitoring. Toxicol. Lett. 77(1-3), 85-91.

Inoue, O., Seiji, K., Watanabe, T., Kasahara, M., et al. (1988). Mutual metabolic suppression between benzene and toluene in man. Int. Arch. Occup. Environ. Health 60, 15-20.

Iwata, M., Takeuchi, Y., Hisanaga, N., and Ono, Y. (1983). Changes of $n$ hexane metabolites in urine of rats exposed to various concentrations of $n$-hexane and to its mixture with toluene or MEK. Int. Arch. Occup. Environ. Health 53, 1-8.

Kežić, S., and Monster, A. C. (1991). Determination of 2,5-hexanedione in urine and serum by gas chromatography after derivatization with $\mathrm{O}$ pentafluorobenzylhydroxylamine and solid phase extraction. J. Chromatogr. 563, 199-204.

Krasavage, W. J., O’Donogue, J. L., DiVincenzo, G. D., and Terhaar, C. J. 
(1980). The relative neurotoxicity of methyl- $n$-butyl ketone, $n$-hexane, and their metabolites. Toxicol. Appl. Pharmacol. 52, 433-441.

Nelder, J. A., and Mead, R. (1965). A simplex method for function minimization. Comput. J. 7, 308-313.

Opdam, J. J. G., and Smolders, J. F. J. (1986). Alveolar sampling and fast kinetics of tetrachloroethylene in man I Alveolar sampling. Br. J. Ind. Med. 43, 814-824.

Opdam, J. J. G. (1989). The respiratory input in inhalation experiments. $B r$. J. Ind. Med. 46, 145-156.

Opdam, J. J. G. (1991). Linear systems dynamics in toxicokinetic studies. Ann. Occup. Hyg. 35(6), 633-649.

Ralston, W. H., Hilderbrand, R. L., Uddin, D. E., Andersen, M. E., and Gardier, R. W. (1985). Potentiation of 2,5-hexanedione neurotoxicity by methyl ethyl ketone. Toxicol. Appl. Pharmacol. 81, 319-327.

Robertson, P., White, E. L., and Bus, J. S. (1989). Effects of methyl ethyl ketone pretreatment on hepatic mixed-function oxidase activity and on in vivo metabolism of $n$-hexane. Xenobiotica 19(7), 721-729.

Shibata, E., Huang, J., Hisanaga, N., Ono, Y., Saito, I., and Takeuchi, Y.
(1990). Effects of MEK on kinetics of $n$-hexane metabolites in serum. Arch. Toxicol. 64, 247-250.

Tardif, R., Goyal, R., and Brodeur, J. (1992). Assessment of occupational health risk from multiple exposure: Review of industrial solvent interaction and implication for biological monitoring of exposure. Toxicol. Ind. Health 8(1-2), 37-52.

Tardif, R., Sato, A., Laparé, S., and Brodeur, J. (1994). Ethanol induced modification of m-xylene toxicokinetics in humans. Occup. Environ. Med. 51, 187-191.

Van Engelen, J. G. M., Kežić, S., Haan, W. de, Opdam, J. J. G., and Wolff, F. A. de (1995a). Determination of 2,5-hexanedione, a metabolite of nhexane, in urine: Evaluation and application of three analytical methods. J. Chromatogr. B 667, 233-240.

Van Engelen, J. G. M. (1995b). Kinetic Interactions between Organic Solvents: Effect of Methyl Ethyl Ketone on n-Hexane Kinetics in Human Volunteers and Rats. Ph.D. thesis, Univ. of Amsterdam, Amsterdam.

Van Engelen, J. G. M., Rebel-de Haan, W., Opdam, J. J. G., and Mulder, G. J. Effect of Methyl Ethyl Ketone (MEK) on the Biotransformation of n-Hexane to 2,5-Hexanedione in the Rat in Vivo during Short Term NoseOnly Co-exposure. in preparation. 